\title{
CONSUMO DA CARNE SUÍNA NO BRASIL: ASPECTOS SIMBÓLICOS COMO DETERMINANTES DOS COMPORTAMENTOS
}

\author{
Danilo Alves Marçal* \\ Rodrigo Caetano de Abreu** \\ Thelma Lucchese Cheung ${ }^{* * *}$ \\ Charles Kiefer ${ }^{* * * * *}$
}

RESUMO: O Brasil é o quarto maior produtor e exportador mundial de carne suína. Entretanto, a ingestão per capita nacional é baixa quando comparada ao volume anual consumido em outros países. Levando-se em consideração os aspectos nutricionais positivos da ingestão dessa proteína em detrimento daquelas que são mais consumidas, bem como o destaque da eficiência brasileira em todos os elos dessa cadeia produtiva, interessou-se nesta revisão de literatura por identificar as diferentes motivações alegadas pelos consumidores quanto à sua inclusão ou rejeição na dieta. Considerando os aspectos simbólicos ligados à incorporação da "carne de porco", justificados nos artigos pesquisados, concluiu-se necessário que campanhas promocionais sejam pensadas com o objetivo de esclarecer a população quanto às atuais e modernas técnicas de produção, à qualidade nutricional da carne suína, à condição sanitária e à facilidade do seu preparo. Faz-se importante que o comensal perceba a carne suína de modo diferente. Tal percepção será resultado da informação fornecida ao consumidor por meio dos rótulos e campanhas publicitárias.

PALAVRAS-CHAVE: Comportamento do consumidor; Consumo de carne suína; Simbolismo.

\section{CONSUMPTION OF PORK IN BRAZIL: SYMBOLIC ASPECTS AS DETERMINING FACTORS IN BEHAVIOR}

ABSTRACT: Brazil ranks fourth as the greatest world producer and exporter of pork, even though the country's per capita consumption is low when compared to the

\footnotetext{
Bolsista FUNDECT, Programa de Pós-graduação em Ciência Animal da Universidade Federal de Mato Grosso do Sul (UFMS), Campo Grande (MS), Brasil; E-mail: danilo.a.marcal@hotmail.com

** Bolsista FUNDECT, Programa de Pós-graduação em Ciência Animal da Universidade Federal de Mato Grosso do Sul (UFMS), Campo Grande (MS), Brasil.

*** Docente do Programa de Pós-graduação em Administração da Universidade Federal de Mato Grosso do Sul, Campo Grande (MS), Brasil.

**** Docente do Programa de Pós-graduação em Ciência Animal da Universidade Federal de Mato Grosso do Sul (UFMS), Campo Grande (MS), Brasil.
} 
volume/year consumed in other countries. While taking into consideration positive nutritional aspects in the consumption of the protein to the detriment of other more consumed ones and the efficiency in all links of the Brazilian production chain, a review of the literature identified several different motivations by consumers with regard to the inclusion or exclusion of pork. The symbolic aspects linked to pork consumption in the papers analyzed revealed that promotional campaigns should be undertaken to inform the population on the modern and current production techniques, the nutritional quality of pork, the sanitary conditions and the ease in preparing it. The consumer should perceive pork from a different point of view, or rather, the result of information given to the consumer through labels and publicity.

KEY WORDS: Consumption of pork; consumers' behavior; Symbolism.

\section{INTRODUÇÃO}

Há mais de dez anos, o Brasil ocupa a quarta posição no ranking mundial de produção de carne suína, sendo China, União Europeia e Estados Unidos os maiores produtores, com produção aproximada de 54, 23 e 11 milhões de toneladas, respectivamente, no ano de 2013. A produção brasileira de carne suína, neste mesmo ano, de acordo com dados da Associação Brasileira da Indústria Produtora e Exportadora de Carne Suína (ABIPECS), foi de aproximadamente 3,4 milhões de toneladas. Quanto aos principais exportadores, em 2013, têm-se Estados Unidos (2,3 milhões de toneladas), União Europeia (2,2 milhões de toneladas), Canadá (1,2 milhões de toneladas) e Brasil (600 mil toneladas) (USDA, 2013). Do total produzido no Brasil, em 2013, 16,6\% foram exportados, sendo que Ucrânia, Rússia e Hong Kong foram os principais importadores, consumindo juntos $67,3 \%$ do total de carne suína exportada pelo Brasil. Entre os Estados brasileiros produtores de suínos, Santa Catarina, Rio Grande do Sul e Paraná foram aqueles que mais se destacaram (ABIPECS, 2013).

Em 2013, o consumo mundial de carne suína foi de aproximadamente 107 milhões de toneladas. Em termos quantitativos, a China se destaca como o país que mais consome este tipo de carne, sendo responsável por 50,6\% do total de carne suína consumida no mundo, muito à frente da União Europeia, que ocupa a 
segunda posição no ranking com o consumo de 18,9\%. Nesse cenário, o consumo de carne suína no Brasil foi o quinto maior, porém correspondendo a apenas 2,6\% do total consumido mundialmente. Entretanto, quando se avalia o consumo per capita, ocorre uma modificação no posicionamento dos países. O maior consumo per capita, em 2011, foi registrado em Hong Kong (66,5 kg/ano), seguido por Macau (54,1 kg/ano) e Belarus (46,5 kg/ano) (USDA, 2013). Na União Europeia, considerando-se cada país separadamente, Alemanha, Espanha e Itália consumiram, respectivamente, $66,0 \mathrm{~kg} / \mathrm{ano}, 54,0 \mathrm{~kg} / \mathrm{ano}$ e $45,0 \mathrm{~kg} / \mathrm{ano}$ (ABCS, 2011).

Vale destacar que, dentre as proteínas consumidas mundialmente, a carne suína é a mais demandada, seguida pela carne de aves e, em terceiro lugar, pela carne bovina (USDA, 2012). Porém, no Brasil, esse padrão de consumo não é observado. Entre os três tipos cárneos, a maior demanda é pela carne bovina. Aves e suínos representam a segunda e a terceira opção proteica para os brasileiros (IBGE, 2012). De acordo com a Pesquisa de Orçamentos Familiares (POF), divulgada pelo IBGE, no período entre 2008 e 2009, o consumo per capita de carne suína in natura no Brasil foi de $3,1 \mathrm{~kg}(7,9 \%)$, enquanto que o de carne bovina e de aves foi de $23,1 \mathrm{~kg}(58,4 \%)$ e $13,3 \mathrm{~kg}(33,7 \%)$, respectivamente. As regiões brasileiras com maior consumo per capita de carne suína in natura são a região Sul (4,4 kg/ano), seguida pelas regiões Centro-Oeste (4,0 kg/ano), Sudeste (3,5 kg/ano), Norte (2,5 kg/ano) e Nordeste (1,7 $\mathrm{kg} / \mathrm{ano}$ ). Acrescentando-se o consumo de produtos industrializados e embutidos de suínos, o volume se torna um pouco mais expressivo quando somado ao consumo de carne suína in natura. Tal consumo, per capita, no ano de 2012, foi de $14,9 \mathrm{~kg}$ (ABIPECS, 2013).

Considerando-se o potencial do Brasil para a produção de suínos, podese inferir que o consumo interno é muito baixo quando comparado ao consumo de outros países. A suinocultura industrial nacional tem passado por constantes evoluções. Segundo o Instituto Brasileiro de Geografia e Estatística (IBGE), em 2012, do total de suínos abatidos, $89 \%$ foram abatidos em frigoríficos com Serviço de Inspeção Federal (SIF), garantido maior segurança para a carne suína produzida no Brasil (IBGE, 2013). Além disso, cabe acrescentar que as raças escolhidas para a produção atingem o peso ideal de abate mais rapidamente, com maior quantidade de carne magra e menor quantidade de gordura na carcaça. Todo o melhoramento no 
padrão de produção é devido às diversas pesquisas relacionadas ao melhoramento genético, às técnicas de reprodução mais avançadas e ao manejo sanitário e nutricional dos animais. Contudo, embora o avanço em qualidade e o rigor sanitário sejam características importantes da cadeia produtiva de carne suína brasileira, não há evoluções de destaque quanto ao volume consumido internamente.

Poder-se-ia justificar o baixo consumo de carne suína no Brasil por diferentes fatores técnicos apontados na literatura. Pensando-se sobre a maior demanda por carne bovina em detrimento da suína no Brasil, sugere-se como uma primeira justificativa o fato da atividade de engorda de bovinos ter os menores custos de produção nas fazendas brasileiras, enquanto as aves comercializadas em diferentes canais de distribuição têm preço menor comparado ao preço da carne suína.

Contudo, para o caso específico da carne suína, dados micro e macroeconômicos não são capazes de explicar isoladamente a diferença na ordem de proteínas consumidas no Brasil e no resto do mundo. Considera-se, neste trabalho, que o baixo consumo de carne suína no Brasil está mais relacionado a aspectos simbólicos do que utilitários, relacionados apenas aos aspectos nutricionais da ingestão dessa proteína. Para amparar tal discussão, além da apresentação de resultados de trabalhos nacionais acerca das principais motivações relacionadas ao consumo e à rejeç̧ão da carne suína, segundo opiniões de consumidores de diferentes regióes do país, serão apresentadas algumas teorias desenvolvidas pela sociologia e antropologia da alimentação que permitem uma análise mais explicativa e menos descritiva dos comportamentos humanos. As conclusões deste artigo poderão ser úteis aos diferentes agentes da cadeia produtiva de suínos, sobretudo para a formulação de políticas mais eficientes à jusante.

\section{AS RAZÕES DO CONSUMO DE CARNE SUÍNA EM DIFERENTES REGIÓES DO BRASIL}

Os dados apresentados neste tópico são referentes aos resultados de alguns estudos sobre as motivações quanto ao consumo de suínos no país (Quadro 1). Embora muitos artigos tenham sido encontrados, julgou-se interessante compilar informações sobre os comportamentos de consumidores de diferentes regiões. 
Dessa forma, comentam-se, a seguir, dados de estudos realizados no Sudeste, Centro-Oeste, Nordeste e Sul do Brasil.

Quadro 1. Características relacionadas ao consumo, ou não, de carne suína, em diferentes regiões do Brasil

\begin{tabular}{|c|c|c|c|}
\hline \multirow{2}{*}{ Região } & \multicolumn{2}{|r|}{ Atributos } & \multirow{2}{*}{ Referência } \\
\hline & Positivos & Negativos & \\
\hline \multirow{3}{*}{ Sudeste } & Sabor & $\begin{array}{l}\text { Altos teores de gordura e colesterol; } \\
\text { perigo para saúde }\end{array}$ & Faria et al. (2006) \\
\hline & & & \\
\hline & Sabor & $\begin{array}{l}\text { Gordurosa; fatores sanitários; não } \\
\text { apreciam; falta de costume }\end{array}$ & $\begin{array}{l}\text { Antonangelo et al. } \\
\qquad(2011)\end{array}$ \\
\hline $\begin{array}{l}\text { Centro- } \\
\text { Oeste }\end{array}$ & $\begin{array}{l}\text { Saborosa; fácil } \\
\text { preparo; macia }\end{array}$ & $\begin{array}{l}\text { Não apreciam a carne; altos teores } \\
\text { de gordura e colesterol }\end{array}$ & Santos et al. (2011) \\
\hline Nordeste & $\begin{array}{l}\text { Preço; sabor; } \\
\text { aparência }\end{array}$ & Gordurosa; "carregada" & Bezerra et al. (2007) \\
\hline Sul & Sabor & $\begin{array}{l}\text { Menos saudável; risco à saúde; } \\
\text { desconforto na produção e abate } \\
\text { dos animais }\end{array}$ & Thoms et al. (2010) \\
\hline
\end{tabular}

Fonte: Dados de pesquisa

O comportamento do mercado consumidor de carne suína e seus derivados em Belo Horizonte (MG), região Sudeste do Brasil, foi estudado por Faria et al. (2006). Nessa pesquisa, o principal motivo apontado pelos consumidores para o consumo da carne suína in natura foi o sabor (65,9\%), enquanto o preço foi pouco mencionado (13,7\%). Foi constatado que $54,6 \%$ dos entrevistados consumiam carne suína in natura e 53,4\% consumiam derivados de carne suína de uma a três vezes por semana. As principais preocupações dos consumidores quanto a tal ingestão foram o teor de gordura ou colesterol $(38,4 \%)$ e o aspecto sanitário, ou seja, o perigo dessa ingestão para a saúde $(27,8 \%)$. Com relação à preferência do consumo 
de proteínas, $35,4 \%$ dos consumidores que participaram daquele estudo afirmaram que preferem carne de aves, $35,4 \%$ carne bovina e $26,7 \%$ a carne suína. A carne de aves foi considerada mais saudável $(70,8 \%)$, seguida pelas carnes bovina (19\%) e suína $(6,2 \%)$. Nos canais de comercialização, a aparência da carne in natura foi considerada como o motivo que mais influenciava a decisão de escolha (44,4\%), enquanto que a origem da carne foi considerada como um fator que influenciava pouco aquela amostra $(71,6 \%)$. Os consumidores justificaram o pouco interesse pela origem do produto, porque a compra da carne in natura era realizada em canais de comercialização da sua confiança. Já no caso dos derivados, a qualidade do produto para os consumidores estava mais relacionada à marca comercial.

Através dos resultados de um estudo realizado em Botucatu, Estado de São Paulo, também localizado na região Sudeste, conduzido por Antonangelo et al. (2011), constatou-se que, em relação ao consumo da carne suína, 90\% dos entrevistados declararam a consumir da seguinte maneira: 2,7\% diariamente, $47,2 \%$ semanalmente, $27,7 \%$ quinzenalmente, $11,1 \%$ mensalmente e $11,1 \%$ em datas festivas. Das pessoas que consumiam semanalmente, aproximadamente, $60 \%$ era na forma industrializada. Entre os que alegaram não consumir maior quantidade de carne suína, cerca de 37,5\% disseram que a consideram gordurosa, 20\% desconfiam das condições sanitárias, $12,5 \%$ disseram que o sabor não agrada, $5 \%$ pelo preço e $25 \%$ por outros fatores como por exemplo falta de cultura de consumo ou religião. Naquele estudo foi observado que o consumo de produtos industrializados era de $58,3 \%$ e o dos produtos in natura correspondeu a $41,7 \%$. Do consumo in natura $27,7 \%$ dos entrevistados consumiam todos os cortes, $16,6 \%$ consumiam a bisteca e o lombo, 5,5\% costela e pernil e 2,7\% consumiam, na maioria das vezes, a picanha suína e $25 \%$ consumiam mais de um corte. Constatou-se que os consumidores daquela amostra declararam que apreciam o sabor da carne suína, não se atendo ao preço.

Na região Centro-Oeste do Brasil, Santos et al. (2011) realizaram um estudo sobre o perfil do consumidor e constataram que a carne suína ocupa a quarta posição na preferência dos consumidores, ficando atrás das carnes bovina, de frango e de peixe. Segundo os pesquisadores, as escolhas pelas proteínas mencionadas estão fortemente relacionadas à cultura local, já que a região é produtora de bovinos de corte e famosa pelos rios piscosos. A rejeição ao consumo de carne suína in natura 
foi justificada pelo fato de não apreciarem a carne $(58,3 \%)$ e por considerarem que tem altos teores de gordura e colesterol (13,9\%). Foi constatado que os consumidores até julgam a carne suína como um alimento saboroso, macio e de fácil preparo, mas, sobretudo, pouco saudável, com alto teor de gordura e caro.

No Nordeste brasileiro, os resultados do trabalho desenvolvido na região de Campina Grande (PB) por Bezerra et al. (2007) observaram que a carne bovina era a proteína mais consumida, seguida pelas carnes de frango, suína e de peixe. Os motivos apontados pelos entrevistados sobre a escolha do tipo de carne a ser consumida foi o preço $(39,5 \%)$, seguido pelo sabor $(28,5 \%)$, aparência $(22,75 \%)$ e valor nutritivo (9,25\%). Dos consumidores paraibanos entrevistados, 78,25\% declararam que consumiam carne suína in natura e $21,75 \%$ não. Entre os principais motivos para a rejeição ao consumo da carne suína estavam uma tendência vegetariana $(40,23 \%)$, uma carne muito gordurosa (21,68\%) e uma carne "carregada" (12\%). Os autores não explicaram o que significou para os entrevistados "carne carregada". Grande parte dos entrevistados $(94,25 \%)$ manifestou atração por novos cortes comerciais de carne suína, por exemplo, a picanha e o filé mignon. No momento da compra, a maioria $(78,50 \%)$ se preocupa com a cor, textura, cheiro e apresentação da carne. Os pesquisadores observaram que $51,75 \%$ dos consumidores entrevistados não concordaram que a carne suína possui baixo teor de colesterol, quando comparada com a de frango e a bovina. Para 47,25\% dos consumidores, os suínos são criados em péssimas condições de higiene, $28 \%$ afirmam que eles são criados em razoáveis condições de higiene e $24,25 \%$ não sabem como e em quais são as condições de criação dos suínos.

Na região Sul do país, estudando o perfil do consumidor de carnes, em uma amostra de jovens adultos do município de Irati, no Paraná, Thoms et al. (2010) observaram que $75 \%$ afirmaram consumir carne nas duas principais refeições, praticamente todos os dias da semana. Apenas $7 \%$ dos entrevistados afirmaram consumir uma única vez na semana e $2 \%$ disseram que não consomem esse tipo de alimento. Contudo, quando questionados sobre o consumo semanal de carne suína, $15 \%$ relataram consumi-la mais de uma vez por semana, $26 \%$ uma vez por semana, $16 \%$ uma vez por mês e $17 \%$ afirmaram não consumir esse tipo de proteína. Com relação à preferência, a carne bovina foi apontada como a preferida por $50 \%$ dos entrevistados, seguida pelas carnes suína (33\%) e de frango (17\%). O fator que mais 
influenciou a preferência pelo tipo de carne foi o sabor (66\%). A maior parcela da amostra do estudo apontou a carne suína como a menos saudável (83\%), com maior risco de transmissão de enfermidades $(80 \%)$ e que proporciona menor conforto na produção e abate dos animais (60\%).

Considerando que, de modo geral, nos estudos mencionados a gordura, os prejuízos à saúde humana e o desconhecimento da população quanto aos sistemas de produção de suínos no Brasil representaram as principais justificativas à pouca ingestão ou, até mesmo, à não ingestão dessa carne, julgou-se importante elaborar tópicos sobre ambos os temas. A seguir, constam informações técnicas sobre os aspectos da qualidade nutricional da carne suína e o sistema produtivo dessa cadeia.

\section{QUALIDADE DA CARNE SUÍNA}

A importância de conhecer a composição nutricional da carne está ligada ao efeito dos nutrientes, principalmente dos lipídios, sobre a saúde humana. Sabese que o consumo exagerado de lipídios pode aumentar as chances de doença cardiovascular que é uma das principais causas de morte no Brasil e em muitos países (LIMA et al., 2000).

Os consumidores têm se preocupado mais com o conteúdo nutricional das carnes e, por isso, é importante diferenciar além das espécies, a composição nutricional destas (CANESQUI; GARCIA, 2005). A carne suína é um alimento rico em lipídios, colesterol e ácidos graxos insaturados e saturados. Porém, quando comparada com as carnes de aves e de bovinos não possui diferenças consideráveis quanto aos teores de lipídios, proteínas e colesterol (Tabela 1). 
Tabela 1. Composição centesimal de carne suína, bovina e de frango

\begin{tabular}{lccccc}
\hline Carnes & Umidade, \% & Lipídios, \% & Proteína, \% & $\begin{array}{c}\text { Colesterol, } \\
\mathbf{m g} / \mathbf{1 0 0 g}\end{array}$ & $\begin{array}{c}\text { Valor calórico, } \\
\text { kcal }\end{array}$ \\
\hline Suína (pernil) & $74,96 \pm 0,22^{\mathrm{a}}$ & $1,27 \pm 0,51^{\mathrm{c}}$ & $21,32 \pm 0,19^{\mathrm{b}}$ & $56,97 \pm 5,25^{\mathrm{b}}$ & $96,69 \pm 4,64^{\mathrm{bc}}$ \\
$\begin{array}{l}\text { Bovina (alcatra) } \\
\text { Frango (coxa e }\end{array}$ & $73,52 \pm 0,05^{\mathrm{b}}$ & $2,03 \pm 0,62^{\mathrm{b}}$ & $22,65 \pm 0,11^{\mathrm{a}}$ & $60,96 \pm 1,91^{\mathrm{b}}$ & $108,97 \pm 5,29^{\mathrm{a}}$ \\
sobrecoxa) & $75,39 \pm 0,53^{\mathrm{a}}$ & $3,27 \pm 0,80^{\mathrm{a}}$ & $18,91 \pm 0,37^{\mathrm{c}}$ & $75,94 \pm 1,18^{\mathrm{a}}$ & $105,07 \pm 6,26^{\mathrm{ab}}$ \\
\hline
\end{tabular}

Médias seguidas de letras distintas, na coluna, diferem significativamente entre si pelo teste de Duncan a 5\% de significância.

Fonte: Adaptado de Hautrive et al. (2012).

O medo da incorporação de gordura por parte da população e o desconhecimento sobre a verdadeira composição nutricional dos cortes de carne comercializados fazem com que crenças determinem as escolhas alimentares dos indivíduos, sobretudo aqueles que têm menor acesso às informações. Os ácidos graxos saturados são promotores do desenvolvimento de doenças cardiovasculares (DCV). Em contrapartida, os ácidos graxos insaturados (linoleico e linolênico), ácidos graxos monoinsaturados, fibras dietéticas e antioxidantes têm ação preventiva contra DCV (NORUM, 1992).

Dietas ricas em ácido esteárico (C 18:0) não elevam o colesterol sérico (ULBRICHT; SOUTHGATE, 1991). Ácidos graxos de cadeia curta (abaixo de 10 carbonos) também não aumentam o colesterol no sangue. No entanto, os ácidos graxos láurico (C 12:0), mirístico (C 14:0) e palmítico (C 16:0) podem provocar mudanças degenerativas nas paredes arteriais (HORNSTRA; LUSSENBERG, 1975).

Os valores de lipídios médios totais encontrados na carne e gordura suína são semelhantes em diversos estudos (BRAGAGNOLO; RODRIGUEZ-AMAYA, 1995; 2002; TACO et al., 2006). Entretanto, estas pesquisas constataram que existe variação na quantidade de lipídio nos diferentes cortes (lombo, pernil, paleta e toucinho), sendo o lombo a região com menor teor de gordura. 


\section{CADEIA PRODUTIVA DE SUÍNOS: IMPORTÂNCIA AOS APESCTOS SANITÁ- RIOS E À PRODUTIVIDADE}

A suinocultura brasileira evoluiu, passando de uma atividade de subsistência para uma atividade industrializada de alta eficiência produtiva e controle zootécnico. Diversos são os fatores responsáveis por essa evolução, dentre eles podemos citar: o sistema de produção que passou de um único sítio para vários sítios, os alimentos utilizados nas dietas e a maior fiscalização e controle no abate e processamento da carne (AMARAL et al., 2006).

Alguns pontos importantes na evolução da suinocultura brasileira se devem à utilização de alimentos alternativos e aos aditivos alimentares adicionados às dietas. Os alimentos alternativos utilizados na alimentação dos suínos contribuem para redução do custo de produção e aproveitamento de subprodutos (MELLO et al., 2012), enquanto os aditivos visam a produção de carcaças com menor deposição de gordura e maior deposição de músculo.

$\mathrm{O}$ abate e processamento da carne suína são fiscalizados e regulados pelas Secretarias Municipais de Agricultura, no caso da comercialização municipal; Secretarias Estaduais de Agricultura dos Estados, Territórios e Distrito Federal em se tratando de comercialização intermunicipal; e Ministério da Agricultura, no caso da comercialização interestadual ou internacional, devendo os estabelecimentos estarem previamente registrados no órgão competente antes de entrar em funcionamento (BRASIL, 1989). O atendimento das normas exigidas pelos órgãos competentes garante aos consumidores a qualidade e a segurança da carne suína comercializada pelos estabelecimentos ligados à cadeia produtiva da carne suína.

Apesar de muitas pessoas possuírem um conceito equivocado a respeito da carne suína, existe, cada vez mais, pessoas que estão preocupadas com o bem estar animal, participando mais dos elos de produção da carne, desde a criação. São cuidados que o produtor adota desde o início da cadeia produtiva que refletem e têm participação decisória no rendimento e na qualidade da carne e do produto processado (LUDEWIG et al., 2010).

Os estudos mencionados anteriormente, quanto aos comportamentos de consumo de carne suína em diferentes regiões brasileiras, mostraram que além dos 
consumidores considerarem que a carne suína possui maiores teores de gordura e colesterol, quando comparada às carnes de aves e bovinos, muitos acreditam que os suínos são criados em ambientes sujos e que podem transmitir doenças para as pessoas que consumirem sua carne. Naqueles artigos, muitos consumidores alegaram desconhecer as condições em que os suínos são criados. As imagens dos sistemas antigos e não tecnificados de criação de suínos, criados soltos e sem cuidado sanitário algum, perduraram no consciente coletivo.

$\mathrm{Na}$ suinocultura praticada atualmente, os suínos são criados em instalações limpas com rigoroso controle sanitário. Suínos criados nessas condições não transmitem doenças aos seres humanos. Em granjas com produção industrial, os animais recebem vacinas e medicamentos, toda a alimentação é balanceada e a água fornecida aos animais é tratada (ROPPA, 2002).

Há muitas décadas, os suínos eram criados com o objetivo de fornecer gordura, utilizada na preparação de alimentos. Entretanto, com o surgimento dos óleos vegetais e o esclarecimento da população a respeito dos malefícios à saúde provocados pela ingestão excessiva de gordura levaram ao aperfeiçoamento das técnicas de produção de suínos. Por intermédio de programas de melhoramento genético, nutrição balanceada e manejo sanitário adequado, os suínos produzem carcaças com alto percentual de carne e baixo conteúdo de gordura.

\section{COMPORTAMENTOS ALIMENTARES E A POSSIBILIDADE DE UM NOVO OLHAR DO CONSUMIDOR PARA A CADEIA PRODUTIVA DE SUÍNOS}

Muito mais que um ato biológico, a alimentação humana é um ato social e cultural. Mais que um elemento da chamada "cultura material", a alimentação implica representações e imaginários, envolve escolhas, classificações e símbolos que organizam as diversas visões de mundo no tempo e no espaço. Tomando-se a alimentação humana como um ato cultural, é possível pensá-la como um "sistema simbólico" no qual estão presentes códigos sociais que operam no estabelecimento de relações dos homens entre si e com a natureza. A alimentação se refere a um conjunto de substâncias que uma pessoa ou um grupo costuma ingerir, implicando 
a produção e o consumo, técnicas e formas de aprovisionamento, de transformação e de ingestão de alimentos. Deste modo, a alimentação vai além do biológico, relacionando-se com o social e o cultural (MACIEL, 2004).

As representações simbólicas não são simples coadjuvantes no processo alimentar de consumo da carne. Ao contrário, tais representações não somente estão fortemente presentes, como atuam na compreensão da realidade e orientam práticas e comportamentos, uma vez que são componentes atribuídos às representações sociais (BARROS et al., 2012).

Além da preocupação com a saúde, a sociedade moderna também valoriza a exibição da saúde através de um corpo aparentemente saudável. Por exemplo, estar em má forma ou doente são indicativos de escassez de autocontrole e representam uma falha na gestão pessoal do próprio corpo. Os alimentos possuem qualidades morais incorporadas a eles que podem ser atribuídas aos seus consumidores. Os alimentos podem ser fonte de prazer ou de saúde e a escolha entre os alimentos pode significar autodisciplina ou a satisfação de instintos e impulsos, que pode ser interpretado como uma fraqueza. Com o surgimento do conceito de alimentação orgânica, os consumidores têm se preocupado com a forma como os alimentos são produzidos e transformados em comida e o impacto de sua produção no meio ambiente. Uma dieta saudável não é mais determinada pela ingestão ou a exclusão de determinados nutrientes, mas a ideia de que a saúde do corpo e do ambiente que estão interligados (BARBERANI, 2012).

Os alimentos têm várias funções e diversos significados e o estudo do consumo alimentar envolve diversas esferas, como história, cultura e economia. A comercialização da carne suína necessita de uma reestruturação para aumentar seu consumo no Brasil. O consumidor precisa saber que a carne suína é uma fonte de proteínas saudável e segura. Mas, além disso, é necessário informar ao consumidor que a carne suína transmite seu aspecto saudável a quem a consome. Tais informações devem estar explícitas nos rótulos. Para transmitir segurança ao consumidor, mesmo a carne suína comercializada in natura, deve ser apresentada junto à marca do frigorífico fornecedor. Como a marca transmite segurança ao consumidor, as empresas deveriam investir na comercialização de cortes menores e já embalados, com rótulos claros e que informem quais as melhores formas de preparo. 
Existe ainda a falta de conhecimento dos consumidores, nesse sentido McCarthy et al. (2004) sugerem que uma das principais razóes para os altos níveis de "confusão" existentes entre os consumidores de carnes é a circulação de informações erradas. No estudo realizado por esses pesquisadores, observou-se que a opinião de médicos e nutricionistas está inserida na avaliação dos consumidores no que diz respeito ao consumo de carne suína, portanto, pode influenciar positiva ou negativamente o consumo.

O consumidor nem sempre tem conhecimento sobre o processo de industrialização sofrido pelo alimento. Nestes casos, os rótulos têm importante papel e podem dar segurança aos consumidores. Com as informações contidas nos rótulos, os consumidores absorvem a ideia que eles transmitem sobre os produtos contidos nas embalagens. Em trabalho realizado em quatro países da Europa, Ngapo et al. (2003) observaram que os consumidores consideram úteis as informações de preço, peso, data de embalagem, data de validade e país de origem expressas nos rótulos das embalagens. Outra informação apontada pelo estudo é que os consumidores europeus têm total confiança na capacidade do açougueiro em selecionar carne de boa qualidade e, além disso, obtida de boas fontes no que diz respeito ao bem-estar animal.

Dransfield et al. (2005) constataram que os consumidores da França, Reino Unido, Suécia e Dinamarca estão dispostos a pagar mais pela carne suína quando os rótulos apresentam informações sobre o local e o sistema de produção dos suínos. Também foi observado que os consumidores preferem cortes de carne suína com pouca gordura.

A carne suína é considerada, por muitos consumidores, como sendo uma carne gordurosa, não apenas no Brasil. Verbeke et al. (2005) observaram que os consumidores belgas preferem a carne suína sem a camada de gordura de cobertura e com menor quantidade de gordura intramuscular. Os consumidores belgas apresentaram desconhecimento com relação ao efeito da gordura intramuscular na carne. Foi apontado pelos consumidores, como justificativa, que a gordura presente entre as fibras musculares pode prejudicar os atributos sensoriais da carne. Na verdade, o que ocorre é o inverso. A gordura realça as características de sabor, suculência e maciez da carne. 
Um projeto realizado pela Associação Brasileira dos Criadores de Suínos (ABCS) em conjunto com o SEBRAE e associações regionais de suinocultores, em 2006, intitulado de "Um novo olhar sobre a carne suína", observou que as principais restrições ao incremento do consumo da carne suína no Brasil são os preconceitos com relação ao impacto sobre a saúde do consumidor, cortes pouco práticos e volumosos, consumo associado a eventos festivos, apresentação inadequada nos pontos-de-venda, quase sempre associada à gordura e a percepção de preço elevado. Uma das ações propostas pelo projeto para aumentar o consumo de carne é a de capacitar o setor varejista desenvolvendo novos cortes de carne suína, a fim de fazer com que o consumo se inicie pela aparência da carne, tanto in natura, quanto a servida em churrascarias e restaurantes.

\section{CONSIDERAÇÕES FINAIS}

O consumo de carne suína sofre grande influência positiva e negativa dos aspectos culturais da população brasileira, uma vez que a importância dos atributos relacionados ao consumo é diferente nos locais estudados, porém, está principalmente relacionada à preocupação dos consumidores com a saúde.

Dada a importância dos aspectos culturais na formação do hábito de consumo, a cadeia produtora de carne suína deve direcionar as atividades de marketing na tentativa de enquadrar a carne suína como um alimento que pode fazer parte do estilo de vida da população. Os rótulos devem informar que a carne suína é segura e saudável, inclusive com mensagens de que os índices de gordura e colesterol são semelhantes e, dependendo do corte, até menores que o de outros tipos cárneos.

Elaborar e divulgar novos cortes e formas de preparo práticas, que não demandem muito tempo, pode aumentar o interesse em consumir a carne suína, não somente em ocasiões festivas, mas também tornar a carne suína uma opção de prato de consumo cotidiano. Além disso, as associações de criadores de suínos devem incentivar a inclusão da carne suína nos cardápios de restaurantes, lanchonetes, escolas e domicílios. 


\section{REFERÊNCIAS}

ASSOCIAÇÃO BRASILEIRA DOS CRIADORES DE SUÍNOS - ABCS. Manual brasileiro de boas práticas na produção de suínos. Brasília: ABCS; MAPA; Concórdia: Embrapa Suínos e Aves, 2011. 140 p.

ASSOCIAÇÃO BRASILEIRA DA INDÚSTRIA PRODUTORA E EXPORTADORA DE CARNE SUÍNA. ABIPECS. Estatísticas. 2013. Disponível em: < http://www.abipecs. org.br/pt/estatisticas.html > . Acesso em: 15 nov. 2013.

AMARAL, A. L.; SILVEIRA, P. D.; LIMA, G.; KLEIN, C. S.; PAIVA, D. D.; MARTINS, F.; KICH, J. D.; ZANELLA, J. R. C.; FÁVRO, J.; LUDKE, J. V.; BORDIN, L. C.; MIELE, M.; HIGARASHI, M. M.; MÓRES, N.; DALLA COSTA, O. A.; OLIVEIRA, P. A. V.; BERTOL, T. M.; SILVAL, V. S. Boas práticas de produção de suínos. Concórdia: EMBRAPA, 2006. (Circular Técnica, 50).

ANTONANGELO, A.; DOLAZZA, R. M.; DUTRA, J. D. B.; RIBEIRO, N. M.; RUV, C. Perfil dos consumidores de carne suína no município de Botucatu - SP. Tékhne e Lógos, v. 2, p. 46-55, 2011.

BARBERANI, S. The Poetics of Food Consumption: Alimentary Rhetorics and Creative Practices. Mediterranean Journal of Social Sciences, v. 3, p. 285-291, 2012.

BARROS, G. S.; MENESES, J. N. C.; SILVA, J. A. D. Representações sociais do consumo de carne em Belo Horizonte. Physis (Rio J.), v. 22, p. 365-383, 2012.

BEZERRA, J. M. M.; CAVALCANTE NETO, A.; DA SILVA, L. D. P. G.; LUI, J. F.; RODRIGUES, A. E.; MARTINS, T. D. D. Caracterização do consumidor e do mercado da carne suína na microrregião de Campina Grande, estado da Paraíba. Ciência Animal Brasileira, v. 8, p. 485-493, 2007.

BRAGAGNOLO, N.; RODRIGUEZ-AMAYA, D. B. Teores de colesterol em carne suína e bovina e efeito do cozimento. Ciência e Tecnologia de Alimentos, v. 8, p. 11-17, 1995.

BRAGAGNOLO, N.; RODRIGUEZ-AMAYA, D. B. Teores de colesterol, lipídios totais e ácidos graxos em cortes de carne suína. Ciência e Tecnologia de Alimentos, v. 22, p. $98-1043,2002$.

BRASIL. Lei $\mathbf{n}^{0} .7 .889$ de 23 de novembro de 1989. Dispõe sobre a Inspeção sanitária e industrial de Produtos de Origem Animal. Secretaria de Inspeção 
de Produto Animal. Secretaria Nacional de Defesa Agropecuária. Ministério da Agricultura. 1989.

CANESQUI, A. M.; GARCIA, R. W. D. Antropologia e nutrição: um diálogo possível. Rio de Janeiro: Fiocruz, 2005. p. 23-47.

DE LIMA, F. E. L.; DE MENEZES, T. N.; TAVARES, M. P.; SZARFARC, S. C.; FISBERG, R. M. Ácidos graxos e doenças cardiovasculares: uma revisão. Revista de Nutrição, v. 13, p. $73-80,2000$.

DRANSFIELD, E.; NGAPO, T. M.; NIELSEN, N. A.; BREDAHL, L.; SJÖDÉN, P. O.; MAGNUSSON, M.; CAMPO, M. M.; NUTE, G. R. Consumer choice and suggested price for pork as influenced by its appearance, taste and information concerning country of origin and organic pig production. Meat Science, v. 69, p. 61-70, 2005.

FARIA, I. G.; FERREIRA, J. M.; GARCIA, S. K. Mercado consumidor de carne suína e derivados em Belo Horizonte. Arquivo Brasileiro de Medicina Veterinária e Zootecnia, v. 58, p. 251-256, 2006.

HAUTRIVE, T. P.; MARQUES, A. C.; KUBOTA, E. H. Avaliação da composição centesimal colesterol e perfil de ácidos graxos de cortes cárneos comerciais de avestruz, suíno, bovino e frango. Alimentos e Nutrição Araraquara, v. 23, p. 327-334, 2012.

HORNSTRA, G.; LUSSENBERG, R. N. Relationship between the type of dietary fatty acid and the arterial thrombus tendency in rats. Atherosclerosis, v. 22, p. 499-516, 1975.

IBGE - Instituto Brasileiro de Geografia e Estatística. Indicadores IBGE: Estatística da produção pecuária. Brasília: IBGE, 2013. 70 p.

IBGE - Instituto Brasileiro de Geografia e Estatística. Pesquisa de orçamentos familiares: perfil das despesas no Brasil. Brasília: IBGE, 2012. 164 p.

LUDEWIG, D. R.; ASSAD, F. T.; MORAES, K. K.; COSTA, N. J.; SANTOS, V. C. Processamento de embutidos e defumados de carne suína. In: ENCONTRO DE ENGENHARIA DE PRODUÇÃO AGROINDUSTRIAL FECILCAM, 4., 2010, Campo Mourão. Anais... Campo Mourão: FECILCAM, 2010.

MACIEL, M. E. Uma cozinha à brasileira. Revista Estudos Históricos, v. 33, p. 25-39, 2004. 
MCCARTHY, M.; O'REILLY, S.; COTTER, L.; BOER, M. Factors influencing consumption of pork and poultry in the Irish market. Appetite, v. 43, p. 19-28, 2004.

MELLO, G.; LAURENTIZ, A. C.; FILARDI, R. S.; BERGAMASCHINE, A. F.; OKUDA, H. T.; LIMA, M. M.; JUNQUEIRA, O. M.; Farelo de algodão em rações para suínos nas fases de crescimento e terminação. Archivos de Zootecnia, v. 61, p. 56-62, 2012.

NGAPO, T. M.; DRANSFIELD, E.; MARTIN, J. F.; MAGNUSSON, M.; BREDAHL, L.; NUTE, G. R. Consumer perceptions: pork and pig production. Insights from France, England, Sweden and Denmark. Meat Science, v. 66, p. 125-134, 2003.

NORUM, K. R. Dietary fat and blood lipids. Nutrition Reviews, v. 50, p. 30-37, 1992. ROPPA, L. A. Suinocultura na América Latina. In: CONGRESSO LATINO AMERICANO DE SUINOCULTURA, 2002. Anais... Foz do Iguaçu, PR: Ed: Embrapa; CNPSA, 2002.

SANTOS, T. M. B.; CAPPI, N.; SIMÕES, A. R. P.; SANTOS, V. A. C. D.; PAIANO, D.; GARCIA, E. R. D. M. Diagnóstico do perfil do consumidor de carne suína no município de Aquidauana - MS. Revista Brasileira de Saúde e Produção Animal, v. 12, p. 1-13, 2011.

TACO: Tabela de composição de alimentos. 2. ed. Campinas: NEPA/UNICAMP, 2006. p. 113. THOMS, E.; ROSSA, L. S.; VON ROSEN STAHLKE, E.; FERRO, I. D.; DE MACEDO, R. E. F. Perfil de consumo e percepção da qualidade da carne suína por estudantes de nível médio da cidade de Irati, PR. Revista Acadêmica: Ciências Agrárias e Ambientais, v. 8, p. 449-459, 2010.

ULBRICHT, T. L. V.; SOUTHGATE, D. A. T. Coronary heart disease: Seven dietary factors. Lancet, v. 38, p. 985-992, 1991.

USDA - United States Department of Agriculture. Livestock and Poultry: World Markets and Trades. Foreign Agricultural Service. 2013. Disponível em: < http://apps. fas.usda.gov/psdonline/circulars/livestock_poultry.pdf> . Acesso em: 12 jan. 2014.

VERBEKE, W.; DE SMET, S.; VACKIER, I.; VAN OECKEL, M. J.; WARNANTS, N.; VAN KENHOVE, P. Role of intrinsic search cues in the formation of consumer preferences and choice for pork chops. Meat Science, v. 69, p. 343-354, 2005.

Recebido em: 28 de setembro de 2014 Revisado em: 17 de setembro de 2015 Aceito em: 22 de dezembro de 2015 